\title{
The influence of age and gender on ultra-rapid categorization
}

Steven Vanmarcke \& Johan Wagemans

Laboratory of Experimental Psychology, University of Leuven, Belgium

\begin{tabular}{|c|c|c|c|c|c|c|c|}
\hline Introduction & \multicolumn{7}{|c|}{ Current study description } \\
\hline \multirow{5}{*}{$\begin{array}{l}\text { Participants get a clear categorization goal in advance } \\
\text { and succeed at detecting the object (animal) almost } \\
\text { perfectly. Studies consistently report population-level } \\
\text { reaction time differences in performance on different } \\
\text { categorization tasks explained by a superordinate } \\
\text { advantage (animal vs dog), perceptual similarity } \\
\text { (animals vs vehicles) and object category size } \\
\text { (natural vs animal vs dog). }\end{array}$} & Variable & All & $\begin{array}{c}\text { Adolescent } \\
\text { boys }\end{array}$ & $\begin{array}{l}\text { Adolescent } \\
\text { girls }\end{array}$ & $\begin{array}{c}\text { Adult } \\
\text { men }\end{array}$ & $\begin{array}{c}\text { Adult } \\
\text { women }\end{array}$ & \\
\hline & $\begin{array}{l}\text { Number of } \\
\text { participants }\end{array}$ & 96 & 24 & 24 & 24 & 24 & \multirow{5}{*}{$\begin{array}{l}\text { - Participants matched on gender, FSIQ and age } \\
\text { - Different ultra-rapid categorization tasks: } \\
\text { - Baseline task } \\
\text { - Animal/vehicle task } \\
\text { - Social task } \\
\text { - Focus on age and gender }\end{array}$} \\
\hline & Age & $\begin{array}{l}17.042 \\
(.418)\end{array}$ & $\begin{array}{l}13.208 \\
(.307)\end{array}$ & $\begin{array}{l}13.348 \\
(.271)\end{array}$ & $\begin{array}{c}20.667 \\
(.424)\end{array}$ & $\begin{array}{c}20.917 \\
(.306)\end{array}$ & \\
\hline & Full Scale IQ & $\begin{array}{c}107.406 \\
(.791)\end{array}$ & $\begin{array}{l}108.125 \\
(2.005)\end{array}$ & $\begin{array}{l}106.717 \\
(1.444)\end{array}$ & $\begin{array}{l}108.313 \\
(1.436)\end{array}$ & $\begin{array}{l}106.771 \\
(1.465)\end{array}$ & \\
\hline & Verbal IQ & $\begin{array}{c}110.281 \\
(.780)\end{array}$ & $\begin{array}{l}110.458 \\
(1.886)\end{array}$ & $\begin{array}{l}109.217 \\
(1.678)\end{array}$ & $\begin{array}{l}109.083 \\
(1.464)\end{array}$ & $\begin{array}{l}112.083 \\
(1.404)\end{array}$ & \\
\hline $\begin{array}{l}\text { In a previous study (Vanmarcke \& Wagemans, 2015), } \\
\text { we replicated these separate findings and found } \\
\text { subtle, yet consistent, gender differences in } \\
\text { typically developing adults (women faster than men). }\end{array}$ & Performal IQ & $\begin{array}{l}104.531 \\
(1.193)\end{array}$ & $\begin{array}{l}105.792 \\
(2.751)\end{array}$ & $\begin{array}{l}104.217 \\
(1.957)\end{array}$ & $\begin{array}{l}107.542 \\
(2.432)\end{array}$ & $\begin{array}{l}101.458 \\
(1.193)\end{array}$ & \\
\hline
\end{tabular}

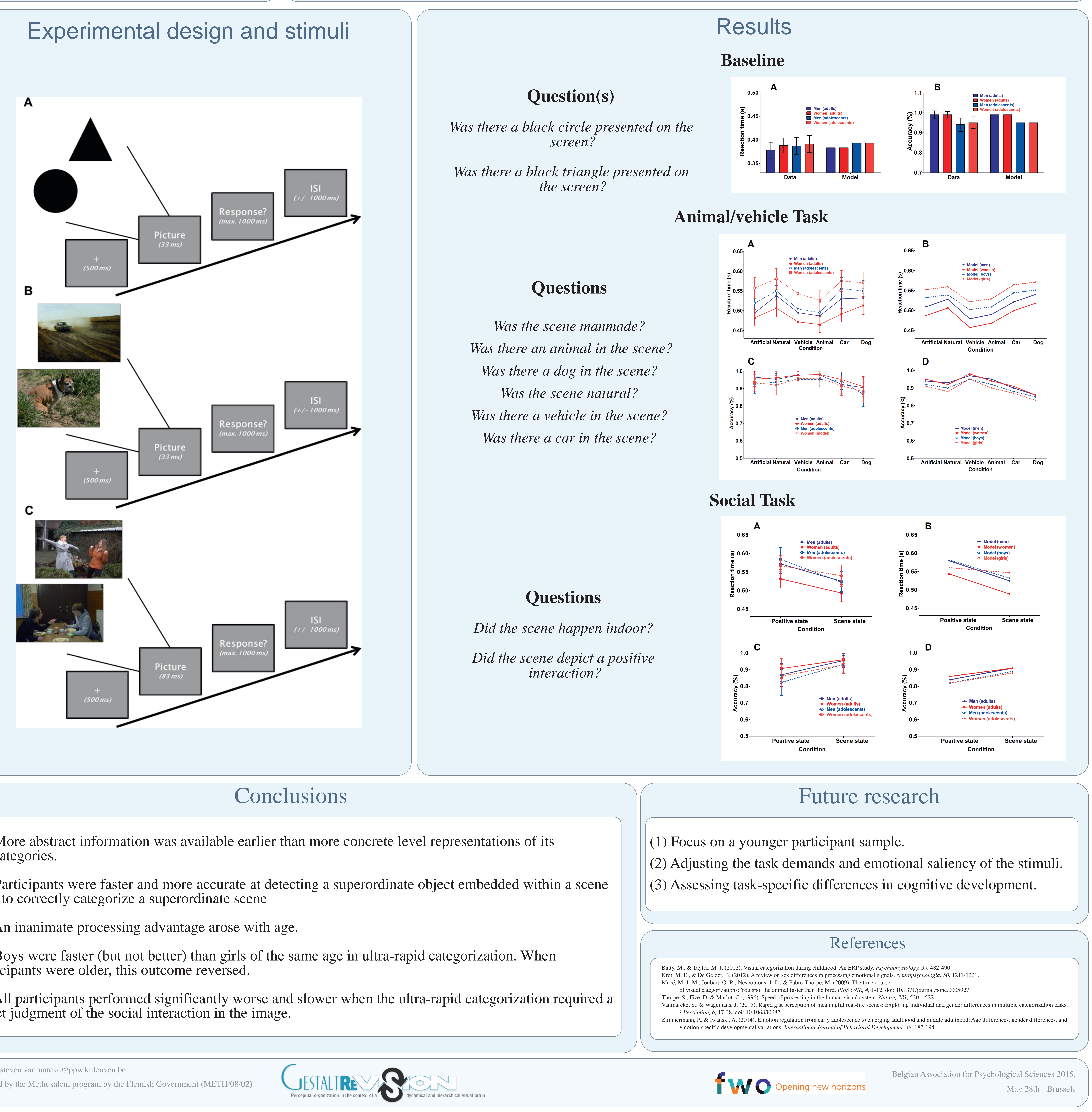

